\title{
PENINGKATAN AKTIVITAS FISIK DAN PEMANFAATAN PEKARANGAN RUMAH UNTUK TANAMAN OBAT KELUARGA (TOGA) SEBAGAI GERAKAN MASYARAKAT HIDUP SEHAT (GERMAS) DI KELURAHAN KENALI ASAM BAWAH
}

\author{
Faridah $^{1)}$, Iin Indrawati ${ }^{2)}$ \\ ${ }^{1,2}$ Prodi D-III Keperawatan, STIKes Baiturrahim Jambi \\ Email.faridah_rty@yahoo.co.id
}

\begin{abstract}
Health is an investment to develop the economy and has an important role in poverty alleviation efforts. Health problems that exist in the community are very many and varied. House-to-house tracking is the most effective way to find out how real health problems are being faced by the community. The target will be achieved by doing physical activities such as sports and cleaning the house, eating vegetables and fruit so that the body is healthy, regular health checks, even in good health, not smoking and not consuming alcohol, cleaning the living environment, using the toilet. While the expected output is doing homework such as washing dishes, washing clothes, mopping and so on is physical activity, it is better if coupled with exercise, such as morning walks, increasing consumption of fruits and vegetables, stopping smoking and not consuming alcoholic beverages, medical checks up although in a healthy condition, together with the surrounding community do the work of cleaning the local environment, using the latrine properly as a place of disposal.The method of implementation carried out is by following counseling about how to run a healthy lifestyle in the family and surrounding environment, counseling about how families and communities run a healthy lifestyle so as to avoid various diseases.
\end{abstract}

Keywords: community movement, living, healthy

\begin{abstract}
ABSTRAK
Kesehatan merupakan investasi untuk membangun ekonomi serta memiliki peran penting dalam upaya penanggulangan kemiskinan. Masalah kesehatan yang ada di masyarakat sangatlah banyak dan beragam macamnya. Penelusuran dari rumah ke rumah merupakan cara yang paling efektif untuk mengetahui cara nyata masalah kesehatan yang sebenarnya sedang dihadapi masyarakat. Target yang akan dicapai adalah dengan cara melakukan aktivitas fisik seperti olahraga dan membersihkan rumah, makan sayur dan buah agar tubuh sehat, cek kesehatan secara rutin, walaupun dalam keadaan sehat, tidak merokok dan tidak mengkonsumsi alkohol, membersihkan lingkungan tempat tinggal, menggunakan jamban. Sedangkan Luaran yang diharapkan adalah melakukan pekerjaan rumah seperti mencuci piring, mencuci pakaian,mengepel dan sebagainya merupakan aktivitas fisik, lebih baik jika ditambah dengan olahraga, seperti jalan pagi, memperbanyak konsumsi buah dan sayur, berhenti merokok dan tidak mengkonsumsi minuman yang beralkohol, medical cek up walaupun dalam kondisi sehat, bersama masyarakat sekitar melakukan kerjabakti membersihkan lingkungan setempat, menggunakan jamban dengan baiksebagai tempat pembuangan.Metode pelaksanaan yang dilakukan adalah dengan cara mengikuti penyuluhan-penyuluhan tentang bagaimana menjalankan pola hidup sehat di keluarga maupun dilingkungan sekitarnya, penyuluhan tentang bagaimana keluarga dan masyarakat menjalankan pola hidup sehat sehingga terhindar dari berbagai macam penyakit.
\end{abstract}

Kata Kunci : gerakan masyarakat, hidup sehat 


\section{PENDAHULUAN}

Masalah kesehatan yang ada di masyarakat sangatlah banyak dan beragam macamnya. Penelusuran dari rumah ke rumah merupakan cara yang paling efektif untuk mengetahui cara nyata masalah kesehatan yang sebenarnya sedang dihadapi masyarakat.

Sebagian masyarakat ada yang menyadari bahwa ada masalah kesehatan yang sedang dialami dan sebagian masyarakat juga ada yang tidak menyadari bahwa terdapat masalah kesehatan yang dialami.

Hidup sehat merupakan suatu hal yang seharusnya memang diterapkan oleh setiap orang, mengingat manfaat kesehatan yang sangat penting bagi setiap manusia, mulai dari kosentrasi dalam bekerja dan beraktivitas dalam kehidupan sehari-hari tentu memerlukan kesehatan baik kesehatan pribadi maupun kesehtan anak serta keluarga.Untuk mencapai keharmonisan keluarga.

Menciptakan hidup sehat sebenarnya sangatlah mudah serta murah dibandingkan biaya yang harus kita keluarkan untuk pengobatan apabila mengalami gangguan kesehatan. Akan tetapi yang kebanyakan terjadi sudah mengidap penyakit baru mengobati sehingga akan membuat kerugian tersendiri bagi yang mengalaminya.

Menteri Kesehatan Republik Indonesia telah membuat Pedoman Prilaku Hidup Bersih dan Sehat yang tertuang dalam Peraturan Menteri Kesehatan Republik Indonesia Nomor : 2269/MENKES/PER/XI/2011 yang mengatur upaya peningkatan perilaku hidup bersih dan sehat atau di singkat PHBS di seluruh Indonesia dengan mengacu kepada pola manajemen PHBS, mulai dari tahap pengkajian, perencanaan dan pelaksanaan serta pemantau dan penilaian. Upaya tersebut dilakukan untuk memberdayakan masyarakat dalam memelihara, meningkatkan dan melindungi kesehatannya, sehingga masyarakat sadar, mau dan mampu secara mandiri ikut aktif dalam meningkatkan status kesehatannya.

Perilaku Hidup Bersih dan Sehat (PHBS) adalah semua perilaku kesehatan yang dilakukan atas kesadaran sehingga anggota keluarga atau keluarga dapat menolong dirinya di bidang kesehatan dan dapat berperan aktif dalam kegiatan kegiatan kesehatan di masyarakat (Depkes RI, 2007)

Pemberdayaan masyarakat harus dimulai dari Rumah Tangga atau keluarga, karena rumah tangga yang sehat merupakan asset atau modal pembangunan di masa depan yang perlu dijaga, ditingkatkan dan dilindungi kesehatnnya. Beberapa anggota rumah tangga mempunyai masa rawan terkena penyakit menular, oleh karena itu untuk mencegah penyakit tersebut, anggota rumah tangga perlu diberdayakan untuk melaksanakan PHBS (Depkes, 2013)

\section{TARGET DAN LUARAN}

Target pengabdian masyarakat ini diharapkan masyarakat kenali Asam bawah mampu melakukan kegiatan aktivitas fisik, makan sayur dan buah, cek kesehatan secara rutin, tidak merokok dan mengkonsumsi alkohol, membersihkan lingkungan tempat tinggal, menggunakan jamban

Luaran tercapai setelah pelaksanaan pengabdian masyarakat ini adalah masyarakat Kenali Asam bawah melakukan pekerjaan rumah seperi mencuci piring, mencuci pakaian, mengepel lantai dan sebagainya, olahraga secara rutin seperti jalan pagi,memperbanyak mengkonsumsi sayuran dan buah-buahan, tidak merokok dan tidak minuman beralkohol, medikal cek up baik yang sedang menderita sakit maupun yang sehat, bersama tetangga dan masyarakat sekitar melakukan kerja bakti membersihkan 
lingkungan, menggunakan jamban dengan baik sebagai tempat pembuangan

\section{METODE PELAKSANAAN}

Program Pelaksanaan Sehatmenjadi momentum bagi masyaraka guna membudayakan pola hidup sehat. GERMAS adalah suatu tindakan sistematis dan terencana yang dilakukan secara bersama-sama oleh seluruh komponen bangsa dengan kesadaran, kemauan, dan kemampuan berprilaku sehat untuk meningkatkan kualitas hidup. Pelaksanaan GERMAS harus dimulai dari keluarga, karena keluarga adalah bagian kecil dari masyarakat yang membentuk kepribadian, mulai dari proses pembelajaran hingga kemandirian. Maka masyarakat dapat mengetahui melalui : penyuluhan penyuluhan tentang bagaimanamenjalani hidup sehat di keluarga maupun lingkungan disekitarnya dan bagaimana menjalankan pola hidup sehat sehingga terhidar dari berbagai macam penyakit

\section{HASIL PEMBAHASAN}

Kegiatan Pengabdian masyarakat dengan tema "Peningkatan Aktivitas Fisik dan Pemanfaatan Pekarangan Rumah untuk tanaman Obat Keluarga (TOGA) Sebagai Gerakan Masyarakat Hidup Sehat (GERMAS) di Kelurahan Kenali Asam Bawah"diawali dengan penyebaran kuesioner untuk mengetahui "Gambaran Perilaku Hidup Bersih dan Sehat" di Tatanan Rumah Tangga Masyarakat Kenali Asam Bawah Kota Jambi meliputi : Umur, Pendidikan, Pekerjaan, Pengetahuan, Sikap, PHBS, Penyuluhan, Umur rata-rata responden berkisar antara $40 \mathrm{~s} / \mathrm{d} 62$ tahun, Pendidikan rata-rata SD dan SMA, Pekerjaan bertani

Tabel 1. Data Pengetahuan Responden tentang PHBS

\begin{tabular}{lc}
\hline \multicolumn{1}{c}{ Pengetahuan } & Persentasi \\
\hline Tinggi & $57 \%$ \\
Rendah & $43 \%$ \\
Total & $100 \%$ \\
\hline
\end{tabular}

Tabel 2. Data Sikap Responden tentang PHBS

\begin{tabular}{ll}
\hline \multicolumn{1}{r}{ Sikap } & \multicolumn{1}{c}{ Persentasi } \\
\hline Baik & $37 \%$ \\
Kurang Baik & $53 \%$ \\
Total & $100 \%$ \\
\hline
\end{tabular}

Tabel 3. Data PHBS Rumah Tangga

\begin{tabular}{lc}
\hline \multicolumn{1}{c}{ PHBS } & Persentasi \\
\hline Baik & $40 \%$ \\
Kurang Baik & $60 \%$ \\
Total & $100 \%$ \\
\hline
\end{tabular}

Tabel 4. Data Penyuluhan Petugas Kesehatan tentang PHBS

\begin{tabular}{ll}
\hline \multicolumn{1}{c}{ Penyuluhan } & \multicolumn{1}{c}{ Persentasi } \\
\hline Sering & $45 \%$ \\
Kadang-kadang & $55 \%$ \\
Total & $100 \%$ \\
\hline
\end{tabular}

Dari Hasil penyebaran kuesioner tentang "Gambaran Perilaku Hidup Bersih dan Sehat di Tatanan Rumah Tangga Masyarakat Kenali Asam Bawah Kota Jambi" perlu mendapatkan perhatian petugas kesehatan

Perilaku merupakan wujud tindakan seseorang berdasarkan pemahaman dan kemauan terhadap sesuatu yang dihadapi.Sedangkan lingkungan hidup merupakan wahana dimana mahluk dapat bertahan dan berkembang biak.

Untuk mewujudkan sebuah bangsa yang lebih sehat, masyarakat diajak berkomitmen untuk melakukan hidup sehat melalui perilaku hidup bersih dan sehat.

Perilaku Hidup Bersih Dan Sehat adalah upaya untuk memberikan pengalaman belajar atau menciptakan suatu kondisi bagi perorangan, keluarga, kelompok dan masyarakat, dengan membuka jalur komunikasi, memberikan informasi dan melakukan edukasi, untuk meningkatkan pengetahuan, sikap dan perilaku, melalui pendekatan pimpinan (Advokasi), bina suasana (Social Support) dan pemberdayaan masyarakat (Empowerment). Sehingga keluarga dan masyarakat itu dapat menolong dirinya 
sendiri dan berperan aktif dalam kegiatankegiatan kesehatan di masyarakat. Dengan demikian masyarakat dapat mengenali dan mengatasi masalahnya sendiri, terutama dalam tatanan masing-masing, dan masyarakat/dapat menerapkan cara-cara hidup sehat dengan menjaga, memelihara dan meningkatkan kesehatannya.

Rumah Tangga merupakan unit terkecil dalam lingkungan. Perilaku hidup yang bersih dan sehat selayaknya harus diterapkan dan ditanamkan kepada seluruh anggota keluarga.Peranan keluarga dalam sebuah rumah memegang kunci utama untuk meningkatkan kualitas kesehatan sejak dini. Karena jika keluarga sehat, akan membentuk masyarakat yang sehat pula. Untuk itu, Sehat harus diawali dari dalam rumah sendiri.

Dengan menerapkannya terlebih dahulu di lingkungan rumah tangga, maka otomatis akan lebih mudah menerapkan ke lingkungan yang lebih luas lagi, yaitu masyarakat. Karena kondisi sehat dapat dicapai dengan mengubah perilaku dari yang tidak sehat menjadi perilaku sehat, dan menciptakan lingkungan sehat di rumah tangga. Oleh karena itu kesehatan perlu dijaga, dipelihara dan ditingkatkan oleh setiap anggota rumah tangga serta diperjuangakan oleh semua pihak secara keseluruhan (totalitas)

PHBS di Rumah Tangga adalah upaya untuk memberdayakan anggota rumah tangga agar tahu, mau dan mampu melaksanakan perilaku hidup bersih dan sehat serta berperan aktif dalam gerakan kesehatan di masyarakat.PHBS di Rumah Tangga dilakukan untuk mencapai Rumah Tangga Sehat.Rumah tangga sehat berarti mampu menjaga, meningkatkan, dan melindungi kesehatan setiap anggota rumah tangga dari gangguan ancaman penyakit dan lingkungan yang kurang kondusif untuk hidup sehat (Depkes RI, 2007).

PHBS merupakan salah satu strategi yang dapat ditempuh untuk menghasilkan kemandirian di bidang kesehatan baik pada masyarakat maupun pada keluarga, artinya harus ada komunikasi antara kader dengan keluarga/masyarakat untuk memberikan informasi dan melakukan pendidikan kesehatan (Depkes RI, 2007).
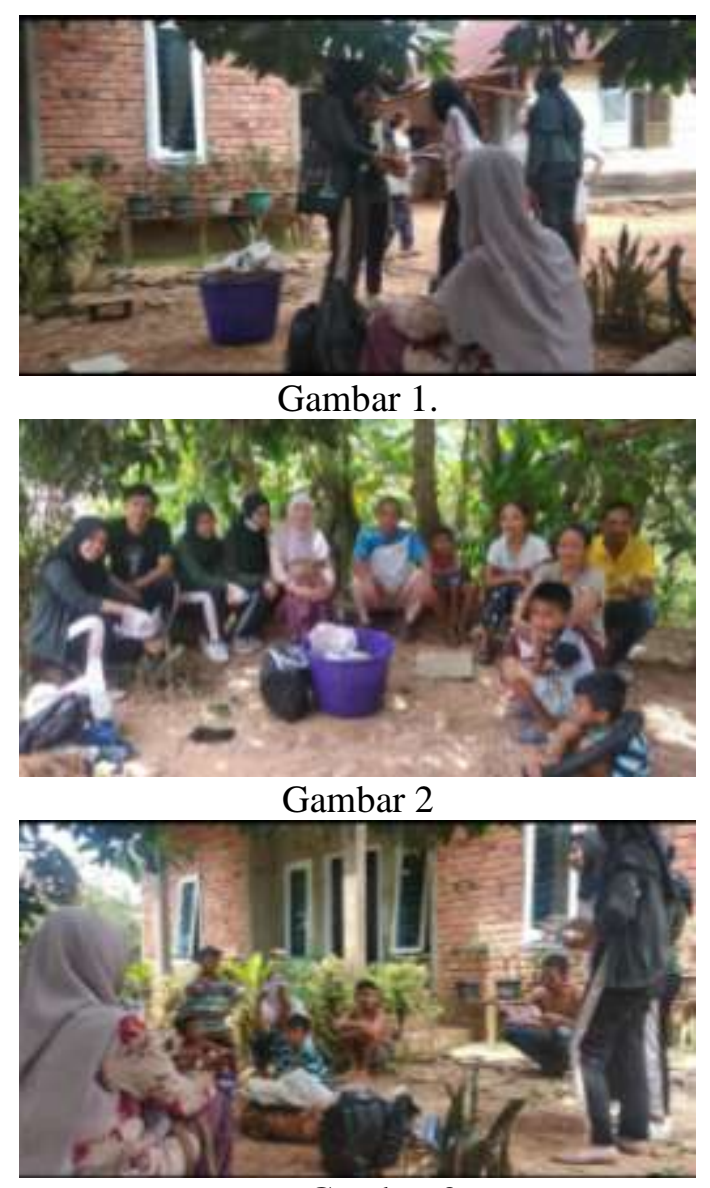

Gambar 3

Gambar 1,2,3.Kegiatan GERMAS

\section{KESIMPULAN DAN SARAN}

Gerakan masyarakat hidup sehat adalah gerakan bersama yang memiliki beberapa tujuan mulai menurunkan beban penyakit menular dan tidak menular, baik kesakitan, kematian maupun kecacatan, menghindari terjadinya penurunan produktivitas, menurunkan beban pembiayaan pelayanan kesehatn karena meningkatnya penyakit dan perbaikan lingkungan serta perubahn prilaku kearah yang lebih sehat perlu dilakukan secara sistematis dan terencana oleh semua komponen bangsa untuk itu 
GERMAS menjadi suatu pilihan dalam mewujudkan derajat kesehatan masyarakat

Hendaknya program GERMAS ini dapat dilakukan secara berkesinmambungan di setiap masyarakat Indonesia khususnya masyarakat Kenali Asam Bawah, agar apa yang kita harapkan pada masyarakat untuk menjadi masyarakat yang sehat jasmani dan rohani. Dengan Program GERMAS.

\section{UCAPAN TERIMAKASIH}

Pengabdian masyarakat ini dapat terwujud dan selesai dengan baik karena adanya bantuan dari berbagai macam pihak maka dari itu penulis mengucapkan terima kasih kepada Ketua STIKES Baiturrahim Jambi, Kaprodi D-III keperawatan STIKES Baiturrahim Jambi, Bapak Lurah Kenali Asam Bawah Kota Jambi yang telah memfasilitasi kegiatan pengabdian masyarakat ini.

\section{DAFTAR PUSTAKA}

Buku Panduan GERMAS (Gerakan Masyarakat Hidup Sehat) 2016

Diana. FM, F. Susanti dan A. Irfan , 2013. Pelaksanaan Program Perilaku Hidup Bersih dan Sehat (PHBS) di SD Negeri 001 Tanjung Balai Karimun. Jurnal Kesehatan Masyarakat .

Kemenkes, 2017 Republik Indonesia. Situs Kementrian Kesehatan Republik Indonesia

Kemenkes RI , 2011. Promosi Kesehatan di Daerah Bermasalah Kesehatan Panduan Bagi Petugas Kesehatan di Puskesmas Jakarta

Pedoman Umum, Program Indonesia Sehat dengan Pendekatan Keluarga, Kementrian Kesehatan Republik Indonesia, 2016 